\title{
CHARACTERISTICS OF BIOGAS PRODUCTION VIA HIGH- TEMPERATURE DRY FERMENTATION OF CHICKEN MANURE AND STRAW
}

\author{
LI, Y. K. ${ }^{1,2}-$ HU, X. M. ${ }^{1}-$ FENG, L. ${ }^{3}$ \\ ${ }^{I}$ School of Resources \& Civil Engineering, Northeastern University, Shenyang 110819, PR China \\ ${ }^{2}$ College of Science, Shenyang Agricultural University, Shenyang 110086, PR China \\ ${ }^{3}$ Liaoning Province Clean Energy Key Laboratory, Shenyang Aerospace University, Shenyang \\ 110136, PR China \\ *Corresponding author \\ e-mail: hxmin_jj@163.com
}

(Received $9^{\text {th }}$ Jan 2020; accepted $6^{\text {th }}$ May 2020)

\begin{abstract}
Dry fermentation has many advantages, such as lower water consumption, high biogas production rates, and low costs. In this paper, chicken manure and straw were combined for dry fermentation at the high temperature of $55 \pm 0.2{ }^{\circ} \mathrm{C}$, and the changes of the production rate, $\mathrm{pH}$, VFAs concentration, and other parameters of the dry fermentation process were analyzed. The results showed that during the stable period, continuous digestion was realized, and the TS content exceeded $20 \%$ in agreement with the characteristics of dry fermentation. In this stage, the TS content, biogas production rate, methane concentration, and $\mathrm{pH}$ were relatively stable. The VFAs content increased with the increase of the loading frequency. At the end of the stable period, the TS contents in high-temperature dry fermentation systems R1, R2, R3, and R4 increased to $21.38 \pm 0.85,22.33 \pm 1.98,23.096 \pm 1.23$, and $27.69 \pm 2.99 \%$, respectively. The biogas production rates maintained at $2.17-2.33,2.40-2.63,2.20-2.44$, and $0.75-0.90 \mathrm{~m}^{3} /\left(\mathrm{m}^{3} \bullet \mathrm{d}\right)$, respectively. The methane contents in biogas stabilized at 53.33-57.22, $64.34-68.88,61.18-66.37$, and $51.32-55.45 \%$, respectively. The systems were stable in operation, should rather be "as were the $\mathrm{pH}$ values and daily gas output. The HRT was determined to be 20 days.
\end{abstract}

Keywords: chicken manure, co-fermentation, high temperature, anaerobic fermentation mechanism

\section{Introduction}

Compared to anaerobic digestion or wet fermentation, dry fermentation has the characteristics of less water consumption, highbiogas production rates, low costs, etc. Nevertheless, dry fermentation is difficult to start, and the parameters of the process are difficult to adjust (Chu et al., 2010; Li et al., 2016; Linke, 2006). Moreover, concentrated ammonia and toxic metabolites inhibit the fermentation process. Thesedrawbacks limit popularization of the dry fermentation technology. In the past two years, encouraged by valorization of biomass resources to avoid the energy crisis, the dry fermentation technique for organic waste attracted more attention due to its advantages. In Western European countries, such as Germany, the dry fermentation technology for biogas production from domestic waste has been developed, especially for market-oriented applications (Zhang and Jahng, 2012; Chen et al., 2008; Duan et al., 2016). In 2000, the dry fermentation capacity of European domestic waste accounted for $54 \%$ of the total fermentation capacity (Tauseef et al., 2013). From 2006 to 2011, the proportion of dry fermentation in newly built anaerobic fermentation units for domestic waste further increased to $63 \%$ (Nasir et al., 2012). To date, dry fermentation is prevalently conducted at medium temperatures, and the feedstock is mainly kitchen waste. Few reports have 
been made on the high-temperature dry fermentation technology using livestock and poultry manure, chicken manure, and straw. The commercial applications of dry anaerobic fermentation mainly consume domestic waste instead of livestock and poultry manure. This is because the nitrogen content in livestock and poultry manure is very high and suppresses fermentation, and ammonia very easily accumulates in the dry fermentation process. Therefore, in this paper, straw was added to regulate the $\mathrm{C} / \mathrm{N}$ ratio in the high-temperature dry fermentation of livestock and poultry manure to shorten HRT and improve the total solid content (TS) in the fermentation liquid above $20 \%$. This technique targets direct feeding and discharging and stable biogas production. The hightemperature fermentation of chicken manure and straw represents a viable technical scheme for valorization of livestock and poultry manure and straw.

\section{Experimental materials and scheme}

\section{Materials and sludge for inoculation}

Chicken manure in the experiment came from a chicken farm in Beipiao County, Chaoyang City, Liaoning Province, China. $100 \mathrm{~kg}$ chicken manure was collected and after careful screening to remove impurities, such as stone, chicken manure collected for continuous $3 \mathrm{~d}$ was sent to the laboratory directly and kept at $4{ }^{\circ} \mathrm{C}$ in refrigerator (Jiménez et al., 2003; Yeoung, 2005). After intensive mixing in the laboratory, the collected chicken manure was used as the experimental material for high temperature anaerobic digestion. The extra $500 \mathrm{~kg}$ of the material was packaged as $1 \mathrm{~kg}$ bags and frozen in refrigerator for a further experiment of continuous high temperature dry fermentation of chicken manure. Stalks used in the experiments, which were from a farm in Shenbei new district, Shenyang City, Liaoning Province, were shipped to the laboratory and cut and ground to 80 mesh.

The inoculated microorganisms in the experiments were from anaerobic digested mud in a northern waste water treatment factory in Shenyang City, Liaoning Province, China. The inoculated active mud was transferred to an airtight plastic container and its temperature decreased to room temperature of about $20^{\circ} \mathrm{C}$ or so during the transportation process (Rundberget et al., 2004; Wang et al., 2018; Zhang et al., 2017), whereas the inoculated mud still maintained active. In the laboratory, the inoculated mud was cultivated and acclimatized at $55^{\circ} \mathrm{C}$. The acquired $5 \mathrm{~L}$ of active mud was transferred to a $25 \mathrm{~L}$ air-tight plastic bag for acclimatization. After $3 \mathrm{~d}$ cultivation at constant $55^{\circ} \mathrm{C}, 2.5 \mathrm{~kg}$ of fresh chicken manure, which was taken in advance and kept at room temperature, was added into active mud after acclimatization for $10 \mathrm{~d}$ cultivation (Hu et al., 2018; Naranjo et al., 2011). In addition, $5 \mathrm{~kg}$ of fresh chicken manure kept at room temperature was acclimatized and cultivated for $10 \mathrm{~d}$ for a further use. Dry material masses of chicken manure, stalks, and inoculated mud were determined after heating in air dry oven for $24 \mathrm{~h}$ at constant temperature of $105^{\circ} \mathrm{C}$ (den Boer et al., 2012). The organic content was determined after $4 \mathrm{~h}$ heating in the muffle furnace at constant $550{ }^{\circ} \mathrm{C}$ (Duan et al., 2016). Main parameters of the wet basic state of chicken manure, stalks, and active mud are shown in Table 1.

\section{Apparatus and methods}

The high-temperature dry fermentation using chicken manure and straw was carried out on the basis of the previous experiment. A $4 \times 30$-liter anaerobic bioreactor (Baoxing, 
Shanghai) was used. The reactor content was stirred regularly through a central controller. Based on the results of the previous experiment, the feedstock with straw mass ratios of $0,3,5$, and $100 \%$ was prepared. During the start-up stage of hightemperature dry fermentation, $3 \mathrm{~L}$ of anaerobic sludge for inoculation, cultivated in Shenyang North Sewage Treatment Plant, was mixed with $3 \mathrm{~kg}$ of the feedstock, and then the mixture was placed into the feeding tank of the bioreactor, which was equipped with an air inlet and outlet. N2 was introduced for 5 min. After oxygen was discharged from the outlet, the feeding valve was opened for the addition of feedstock into the bioreactor. In the experiment, fresh feedstock was added from the top of the bioreactor after spent materials were discharged from the bottom of the bioreactor. For fermentation, the volume of materials was set to $20 \mathrm{~L}$ with water, and the temperature was adjusted to $55 \pm 0.2{ }^{\circ} \mathrm{C}$ (García-Ochoa et al., 1999). During the experiment, $\mathrm{NaHCO} 3$ was added to maintain $\mathrm{pH}$ of the digestion liquid above 6.8 . When the system reached a stable state, hydraulic retention time (HRT) was shortened from 200 to 20 days to increase the total solid content (TS) to higher than 20\%. Direct feeding and discharging and stable biogas production continued until the high-temperature dry fermentation was completed. In the last stage of the experiment, HRT was further shortened to 10 days for a destructive experiment to study the inhibition effect of the high TS content on the dry fermentation process. In the experiment, the biogas production rate, $\mathrm{pH}$, volatile organic acids (VFAs) concentrations, and other parameters of the system were monitored, and the changes and relations of these parameters were analyzed. All the experiments were conducted twice, and the average values were adopted as valid data.

Table 1. Main parameters of the wet basic state of chicken manure, stalks, and active mud

\begin{tabular}{c|c|c|c|c|c}
\hline Parameters & TS:/\% & VS/\% & pH & TC/\% & TN/\% \\
\hline Chicken manure & 27.29 & 23.33 & 6.33 & 46.07 & 4.73 \\
Stalks & 91.44 & 86.50 & 6.89 & 50.02 & 0.88 \\
Active mud & 18.12 & 8.36 & 7.41 & -- & -- \\
\hline
\end{tabular}

TS: Total substance; VS: volatile substance; TC: total carton; TN: total nitrogen

\section{Results and discussion}

\section{Characteristics of biogas production by the high-temperature dry fermentation}

Figures 1-4 show the changes of biogas production rates, methane production rates, and methane contents in reactors R1-4. According to the changes of the loading frequency, biogas production rate, TS concentration, $\mathrm{pH}$, and VFAs concentration, the whole process of high-temperature dry fermentation was divided into four periods: adaptation period (20 days, from day 1 to 20), fast-start period (30 days, from day 20 to 50 ), stable period (70 days, from day 51 to 120), and overload period (20 days, from day 121 to 140). The changes in biogas production rates and relevant parameters in each stage were closely related to the loading frequency. In the adaptation stage, the microorganisms did not completely adapt to the dry fermentation system, and the feedstock amount was small, leading to a low biogas production rate. After the short start-up stage, the system became stable. The temperature and biogas production rate reached high levels. When the fermentation reached the overload stage, in the excess of 
feedstock, the shredded straw expanded due to the high temperature and water uptake, inhibiting the reactions.

In the adaptation period (20 days, from day 1 to 20 ), $1 \mathrm{~kg}$ of feedstock was loaded at the interval of 10 days without discharging. At the same time, $10 \mathrm{~g}$ of sodium bicarbonate $\left(\mathrm{NaHCO}_{3}\right)$ was added to prohibit acidification and reaction inhibition. On the first day of the adaptation period, the TS contents in bioreactors R1-4 were $5.8 \pm 0.25,6.12 \pm 0.65,6.51 \pm 0.55$, and $6.99 \pm 0.87 \%$, and the biogas production rates were as low as $0.15 \pm 0.06,0.09 \pm 0.02,0.08 \pm 0.04$, and $0.01 \pm 0.02 \mathrm{~m}^{3} /\left(\mathrm{m}^{3} \bullet \mathrm{d}\right)$, respectively. In the first 10 days (day 1 to 10) of the adaptation period, the main reason for the decrease of TS concentrations in R1-4 was that the feedstock was loaded only once, and the biochemical reactions took place in the same way as in the previous experiments. In the high-temperature dry fermentation, hydrolysis-acidification microorganisms degraded organic matter in R1-4 reactors to produce organic acids, a small portion of which was digested by anaerobic methanogenic bacteria to yield biogas. Thereby, the TS contents in this stage decreased gradually. On day 10, the TS content decreased to $4.77 \pm 0.16,5.42 \pm 0.56,5.79 \pm 0.77$, and $6.51 \pm 0.24 \%$, respectively. During the adaptation period, the biogas production rate increased gradually. The anaerobic active sludge for inoculation required a period to adapt to the high-temperature anaerobic digestion system. The initial stage of the reaction was similar to a stagnant stage. During the adaptation period, the anaerobic microorganisms could not grow and reproduce themselves immediately because the growth and reproduction could not occur until enzymes for metabolism of nutrients were formed after a while in the fermentation system. The number of anaerobic microorganisms increased along with the process of digestion, and the biogas production rate increased. On day 10 , the biogas production rates in reactors $\mathrm{R} 1-4$ were $0.33 \pm 0.04,0.61 \pm 0.14$, $0.51 \pm 0.07$, and $0.14 \pm 0.03 \mathrm{~m}^{3} /\left(\mathrm{m}^{3} \cdot \mathrm{d}\right)$, respectively. In this stage, feedstock was loaded at the interval of 10 days without discharging, so the HRT (day 1-20) was 200 days. The methane contents in reactors R1-4 increased from 38.45, 39.33, 40.21, and $29.31 \%$ on the first day to $47.21,60.33,54.35$, and $45.33 \%$ on the 20 th day because the number of anaerobic microorganisms increased with the improvement of adaptation to the hightemperature fermentation system. $10 \mathrm{~g}$ of sodium bicarbonate added elevated $\mathrm{pH}$, thus improving the activity of metabolism of methanogenic bacteria and biogas production and increasing the biogas production rate. During this period, because the feedstock in $\mathrm{R} 4$ was only straw, the hydrolysis reaction was inhibited, and acidification took place slowly, so the biogas production rate and methane concentration were significantly lower than those of the other systems with different types of feedstock. To sum up, the process in this stage was similar to that in the previous experiment.

During the fast start-up period (30 days, from day 21 to 50), generally speaking, the TS contents in R1-4 reactors increased because the feedstock was only added without discharging during this period. The HRT (day 21-40) and HRT (day 41-50) was 60 and 40 days, respectively. During this period, the adaptation of anaerobic microorganisms to the high-temperature digestion was enhanced, and the growth rate of microorganisms increased to the maximum. The numbers of hydrolysis-acidification and methanogenic bacteria increased in geometric progression, but the feedstock was only added without discharging, so the feeding rate was higher than the metabolic decomposition rate by microorganisms, resulting in the increase of TS concentration. At the end of this fast start-up period (day 50), the TS content increased to $16.77 \pm 0.65,18.24 \pm 0.29$, $19.35 \pm 1.08$, and $21.44 \pm 1.45 \%$, respectively. During the fast start-up period, the 
biogas production rates in reactors $\mathrm{R} 1-4$ were related to the loading frequency. The production rates increased first and then decreased on each loading day. The reason is that in these days, the easily degradable organic matter in the added materials could be rapidly utilized by the anaerobic microbial community that had adapted to the hightemperature fermentation system, and hydrolysis-acidification and methanation processes occurred in these days, so the biogas production rates were high. Afterwards, the organic residue in straw degraded very slowly, leading to the decrease of biogas production rates. The biogas production rates in reactors $\mathrm{R} 1-4$ increased from $0.78 \pm 0.09, \quad 0.97 \pm 0.11, \quad 0.91 \pm 0.12$, and $0.34 \pm 0.20 \mathrm{~m}^{3} /\left(\mathrm{m}^{3} \cdot \mathrm{d}\right)$ on day 21 to $1.71 \pm 0.12,2.14 \pm 0.18,2.01 \pm 0.08$, and $0.73 \pm 0.07 \mathrm{~m}^{3} /\left(\mathrm{m}^{3} \cdot \mathrm{d}\right)$ in $\mathrm{R} 1,2,3$ and 4 on day 50. The methane concentrations in biogas produced by high-temperature fermentation in R1-4 slightly increased. The reason is that the TS contents in the fast start-up stage increased, and the number of hydrolysis-acidification microorganisms also increased exponentially with the improvement of adaptation, promoting the hydrolysis-acidification process. The adaptation of methanogens to high-temperature anaerobic digestion was slow, and the activity of methanogens increased after the adaptation period that continued for 20 days. The addition of $10 \mathrm{~g}$ of sodium bicarbonate $\left(\mathrm{NaHCO}_{3}\right)$ maintained the $\mathrm{pH}$ of the systems at the level of 6.8 to improve the metabolism activity of methanogens and to enhance the utilization of organic acids in the fermentation liquid to increase the methane concentrations in biogas. On day 50, the methane contents in biogas in reactors R1-4 were 52.31, 66.25, 61.25, and 53.33\%, respectively.

During the stable period (70 days, from day 51 to 120), the TS contents continuously increased. The reason is that in this period, the feedstock was added and waste was discharged every day. Because the feedstock added contained straw, the shredded straw expanded in the high-temperature fermentation systems and floated in the upper layers of CSTR reactors. Although the systems were stirred before discharging, some straw still floated, and the proportion of straw in the materials discharged was relatively small, leading to the gradual increase of TS concentrations in these systems. On day 120 , the TS contents increased to $21.38 \pm 0.85,22.33 \pm 1.98$, $23.096 \pm 1.23$, and $27.69 \pm 2.99 \%$, respectively. During this period, the biogas production rates in reactors R1-4 maintained at 2.17-2.33, 2.40-2.63, 2.20-2.44, and $0.75-0.90 \mathrm{~m}^{3} /\left(\mathrm{m}^{3} \cdot \mathrm{d}\right)$ in $\mathrm{R} 1,2,3$ and 4 . The biogas production rate in reactor $\mathrm{R} 2$ was the highest because the $\mathrm{C} / \mathrm{N}$ ratio in chicken manure and straw was 9.34 and 57.04, respectively. Compared to the reactor $\mathrm{R} 1$ containing pure chicken manure, the content of straw in R2 was increased by $3 \%$, so the carbon content and the $\mathrm{C} / \mathrm{N}$ ratio in the feedstock of R2 were increased, promoting the physiological metabolic activity of the microbial community in the high-temperature dry fermentation process. In the fermentation process, a large amount of organic carbon was transformed into $\mathrm{CH}_{4}$ and $\mathrm{CO}_{2}$ by anaerobic microorganisms. On the other hand, nitrogen was only consumed in the physiological metabolism of microorganisms. When a certain proportion of carbon sources was transformed into methane and carbon dioxide, a certain amount of nitrogen was required to ensure formation of the anaerobic microbial community. The proportion of carbon and nitrogen sources should be appropriate. Therefore, R2 showed the highest biogas production rate of $2.40-2.63 \mathrm{~m}^{3} /\left(\mathrm{m}^{3} \cdot \mathrm{d}\right)$. The methane concentrations in biogas produced in the high-temperature fermentation reactors $\mathrm{R} 1-4$ were relatively stable and maintained at levels of 53.33-57.22, 64.34-68.88, $61.18-66.37$, and $51.32-55.45 \%$ in $\mathrm{R} 1,2,3$ and 4, respectively. The reason is that 
along with the high-temperature fermentation process, the organic substrate in these CSTR reactors was continuously supplied, and the hydrolysis-acidification microorganisms in these systems were balanced with methanogenic microorganisms. The former hydrolyzed and acidified the organic substrate supplied to produce organic acids, which were converted into methane by the methanogens that had adapted to the high-temperature fermentation systems. Therefore, these systems could stably produce biogas without the adjustment of $\mathrm{pH}$, and the organic acids could be directly converted into methane and carbon dioxide. Therefore, the methane concentrations in biogas during this stage were the highest. Feeding and discharging could be realized each day, and $1 \mathrm{~kg}$ of feedstock was added each time. The HRT (day 51-120) was 20 days, and the system was stably operated.

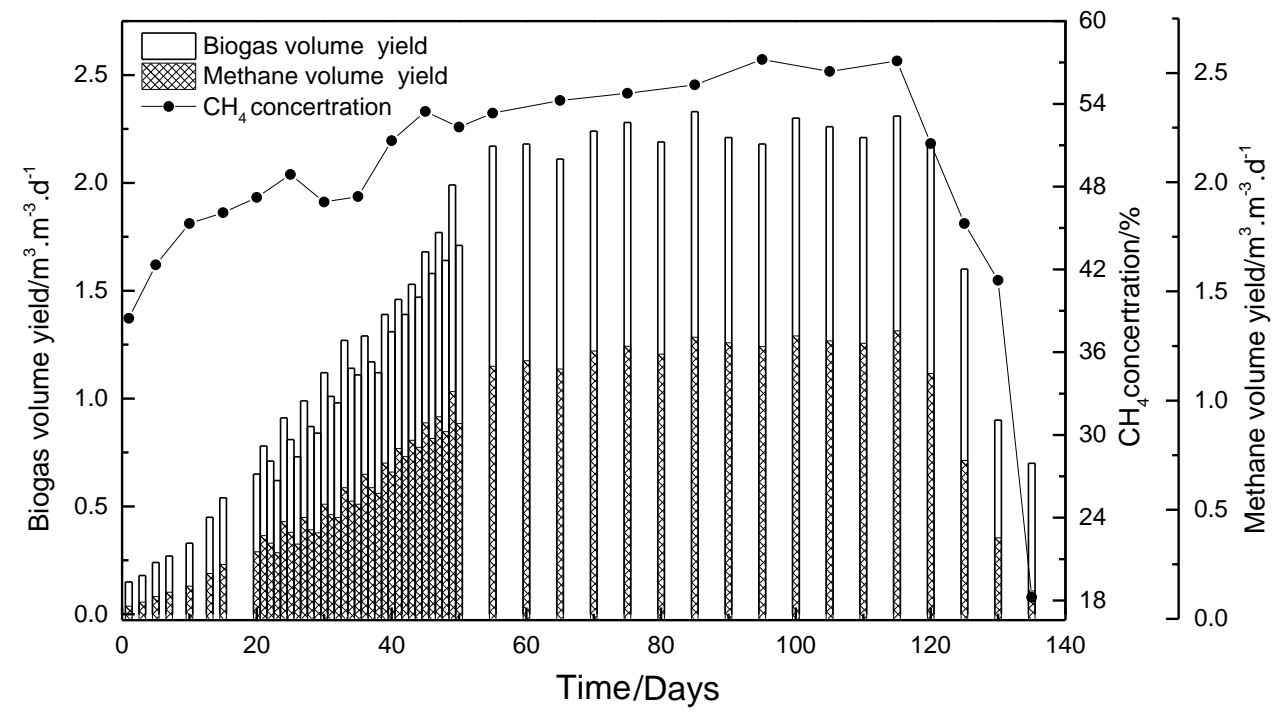

Figure 1. Changes in the biogas production rate, methane production rate, and methane concentration in the high-temperature dry fermentation reactor $R I$

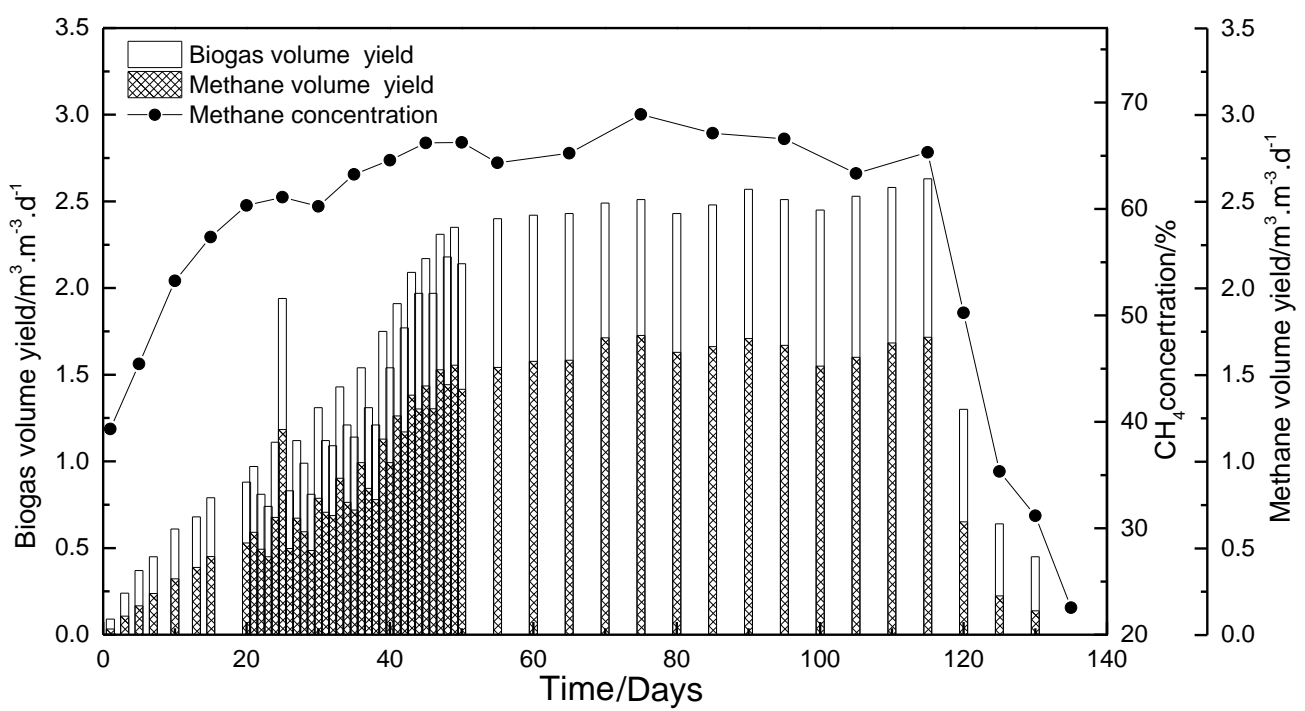

Figure 2. Changes in the biogas production rate, methane production rate, and methane concentration in the high-temperature dry fermentation reactor $R 2$ 


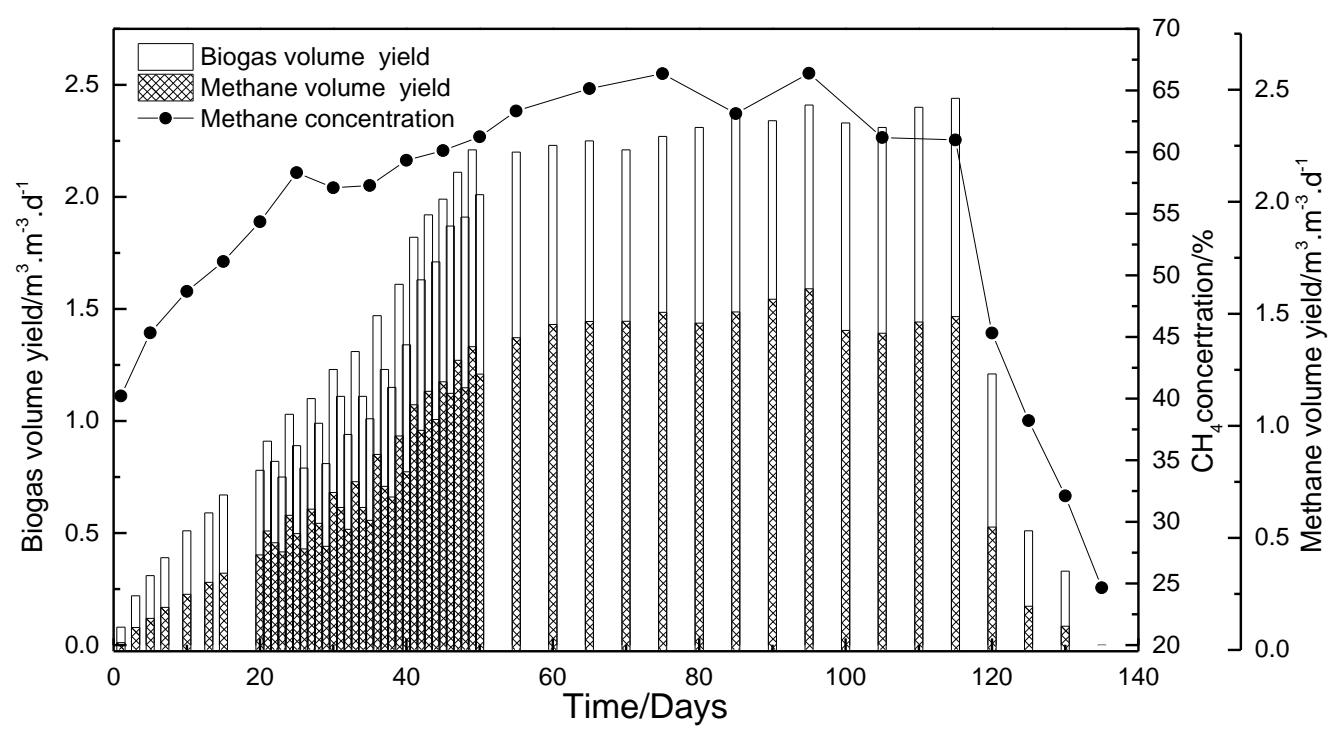

Figure 3. Changes in the biogas production rate, methane production rate, and methane concentration in the high-temperature dry fermentation reactor $R 3$

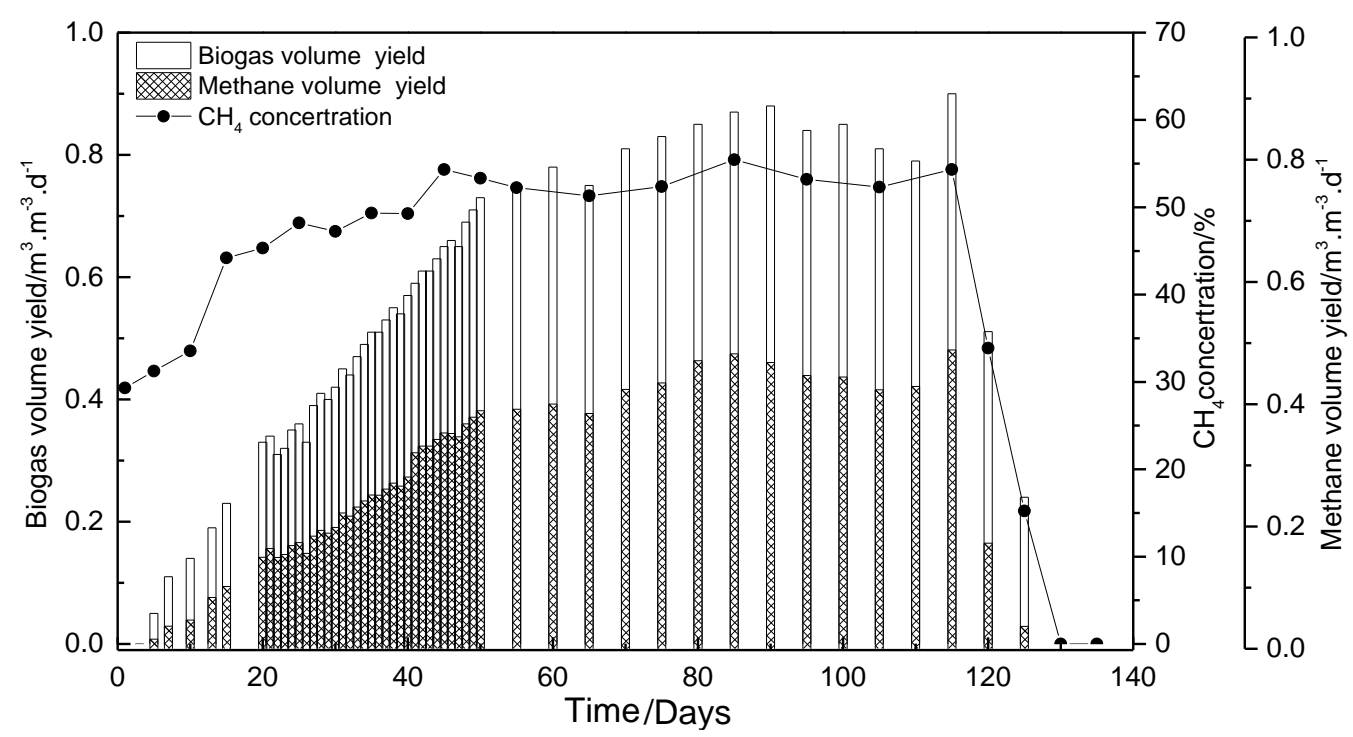

Figure 4. Changes in the biogas production rate, methane production rate, and methane concentration in the high-temperature dry fermentation reactor $R 4$

During the overload period (20 days, from day 121-140), the TS concentrations in these systems significantly increased. The main reason is that when the amount of feedstock was increased, especially in reactors R2, R3, and R4 with straw as the feedstock, the large amounts of shredded straw absorbed water and expanded rapidly at high temperatures. This straw aggregated in the upper layer of CSTR reactors. Although the mixtures were vigorously stirred before discharging, the straw aggregated was difficult to discharge. As a result, the composition of these systems changed, and the proportions of straw increased due to the retention. In the last stage, the straw expanded was hard to stir and discharge, resulting in the decrease of the biogas production rate. And the chicken manure and straw were directly discharged without biochemical 
decomposition. Except R1, reactors R2, R3, and R4 did not yield biogas anymore, and the high-temperature dry fermentation was terminated.

\section{Correlations between pH, TS and VFAs concentrations in the high-temperature dry fermentation}

As shown in Figures 5-8, the changes in pH, TS and VFAs concentrations in the high-temperature dry fermentation reactors R1-4 show that the TS concentrations were positively correlated with the VFAs concentrations in all reactors. The $\mathrm{pH}$ was regulated with $\mathrm{NaHCO}_{3}$ and maintained above 6.8 after 20 days of the adaptation period, which was favorable to the metabolic activity of methanogens. In the overload stage, with the further increase of the TS concentration, the acidification was inhibited, and the $\mathrm{pH}$ decreased. The reactions in reactors $\mathrm{R} 1-4$ were terminated.

In reactors $\mathrm{R} 1-4$, the $\mathrm{pH}$ decreased from day 1 to 10 of the adaptation period. The main reason is that the feedstock was loaded only once in the first 10 days, and the principles of biochemical reactions were similar to those in the previous experiments. During the high-temperature dry fermentation, hydrolysis-acidification microorganisms decomposed organic matter in reactors $\mathrm{R} 1-4$ to produce organic acids, resulting in the decline of $\mathrm{pH}$ in these high-temperature dry fermentation systems. However, the activity of methanogens converting organic acids into methane was relatively low, and the adaptation period of methanogens to the high-temperature dry fermentation systems was longer than that of the hydrolysis-acidification microorganisms. The decrease of $\mathrm{pH}$ further inhibited the metabolism of methanogens and weakened the utilization of organic acids. The $\mathrm{pH}$ declined gradually during the adaptation period (day $1-10$ ), and the $\mathrm{pH}$ on day 10 was $6.11 \pm 0.35,5.39 \pm 0.41,5.45 \pm 0.21$, and $6.75 \pm 0.21$ in $\mathrm{R} 1,2,3$ and 4, respectively. Among these four reactors, the $\mathrm{pH}$ in $\mathrm{R} 2$ declined to the lowest value, and the $\mathrm{pH}$ in $\mathrm{R} 4$ was the highest. The main reason is that the compositions of feedstock were different. In detail, the feedstock in R1, R2, R3, and R4 was pure chicken manure, chicken manure containing 3\% straw, chicken manure containing 5\% straw, and pure straw, respectively. Straw consists of cellulose, hemicellulose, and lignin, which have dense textures, greatly hampering the access of hydrolases into their internal structures and inhibiting hydrolysis reactions in R4. In contrast, the content of straw in R2 was as low as 3\%, so the access of hydrolases was not impeded. Furthermore, the content of carbon in the feedstock of R2 was elevated and thus, the $\mathrm{C} / \mathrm{N}$ ratio was adjusted to promote the physiological metabolism activity of the microbial community in the high-temperature dry fermentation process (Pontes and Pinto, 2006; Linke, 2006; Feng et al., 2013; Lu et al., 2012).

From day 21, the feedstock was added without discharging. In detail, from day 21 to $40,1 \mathrm{~kg}$ of the feedstock was added at the interval of three days; from day 41 to 50 , $1 \mathrm{~kg}$ of the feedstock was added at the interval of two days. At this stage, sodium bicarbonate $\left(\mathrm{NaHCO}_{3}\right)$ was not added, and hence the $\mathrm{pH}$ during the high-temperature dry fermentation in R1-4 declined from $6.65 \pm 0.11,6.53 \pm 0.32,6.58 \pm 0.19$, and $6.54 \pm 0.32$ on day 21 to $6.45 \pm 0.14,6.29 \pm 0.25,6.31 \pm 0.41$, and $6.39 \pm 0.23$ on day 50. In this stage, the VFAs concentrations increased with the increase of TS concentrations and reached $39.87 \pm 2.21, \quad 48.22 \pm 2.89, \quad 41.77 \pm 2.68$, and $11.23 \pm 0.78 \mathrm{~g} / \mathrm{L}$, respectively in $\mathrm{R} 1,2,3$ and 4 , on day 50 . The $\mathrm{pH}$ in the fast start-up period of high-temperature dry fermentation still decreased. The main reason is that after the adaptation stage, the metabolic activity of hydrolysis-acidification microorganisms in the high-temperature dry fermentation significantly improved, and 
the methanogenic microorganisms had long generation time, and the adaptation of methanogenic microorganisms was slower than that of hydrolysis-acidification microorganisms (Zheng et al., 2018; Luo and Li, 2018; Fan et al., 2008). Therefore, the microbial community grew unevenly, and the activity of hydrolysis-acidification microorganisms was higher than that of methanogenic bacteria, resulting in the decrease of $\mathrm{pH}$ and increase of VFAs concentration (Hua and Yong, 2009; Zheng et al., 2018). On the 50th day, the $\mathrm{pH}$ decreased to $6.45 \pm 0.14,6.29 \pm 0.25,6.31 \pm 0.41$, and $6.39 \pm 0.23$, and the VFAs content increased to $39.87 \pm 2.21,48.22 \pm 2.89$, $41.77 \pm 2.68$, and $11.23 \pm 0.78 \mathrm{~g} / \mathrm{L}$ in $\mathrm{R} 1,2,3$ and 4 .

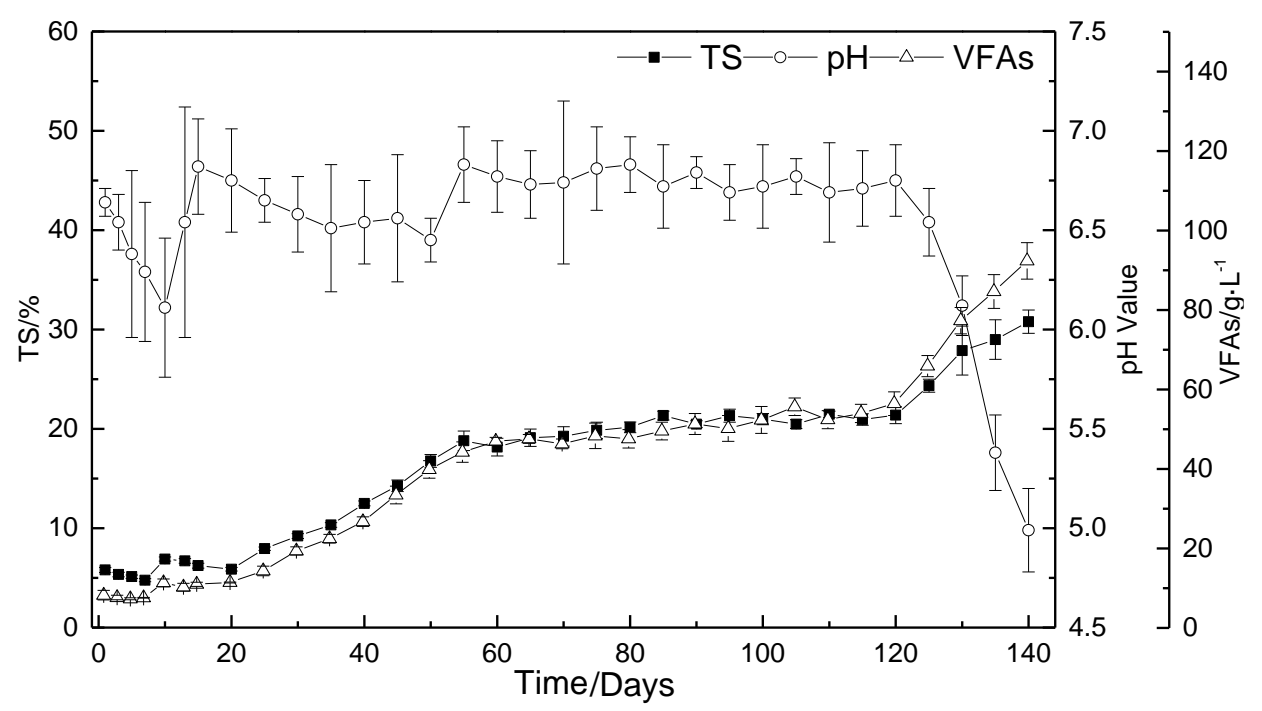

Figure 5. Changes in $p H, T S$ and VFAs concentrations in reactor $R 1$

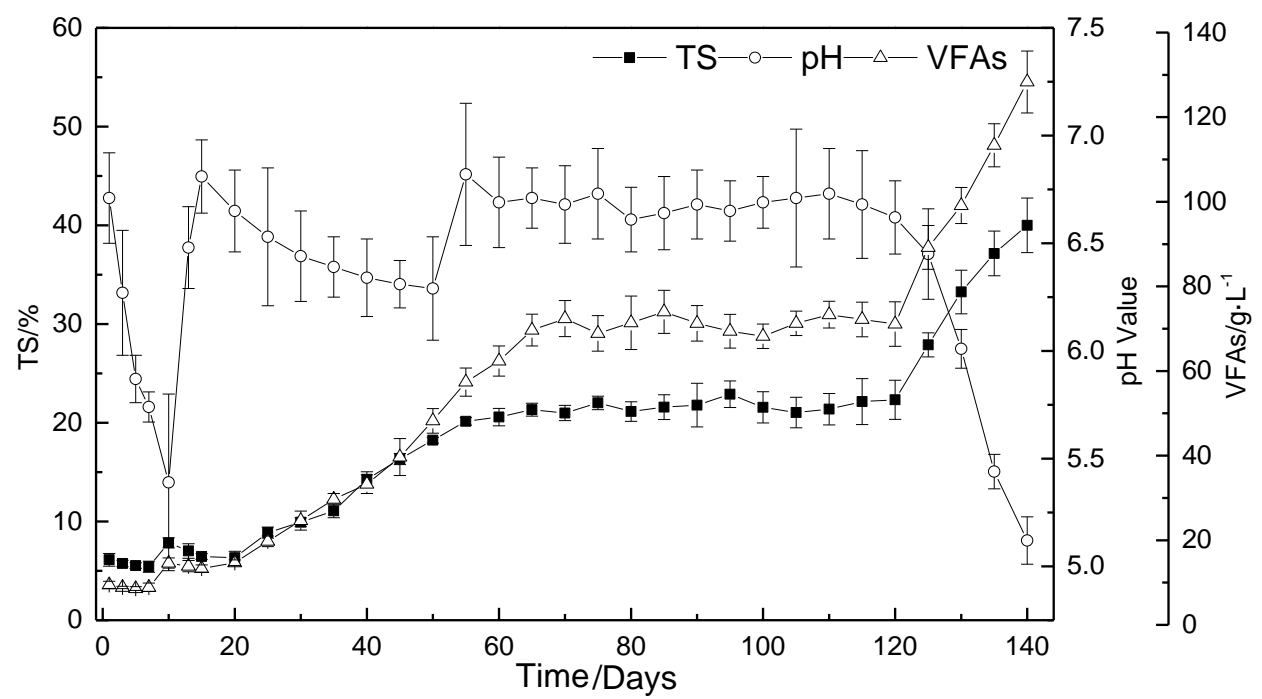

Figure 6. Changes in $p H, T S$ and VFAs concentrations in reactor $R 2$

From day 51, the feedstock was added and discharged every day. In detail, $1 \mathrm{~L}$ of the fermentation liquid was discharged first, and then $1 \mathrm{~kg}$ of the feedstock was added to the CSTR reactors. The volume of each system was increased to $1 \mathrm{~L}$ with water. The TS 
concentrations in these systems continued to increase from $18.80 \pm 0.98,20.15 \pm 0.38$, $20.99 \pm 0.98$, and $23.33 \pm 1.54 \%$ on the 51 st day to $21.38 \pm 0.85,22.33 \pm 1.98$, $23.096 \pm 1.23$, and $27.69 \pm 2.99 \%$ on the 120 th day in R 1, 2, 3 and 4, respectively. Only on the 51st day, $20 \mathrm{~g}$ of sodium bicarbonate $\left(\mathrm{NaHCO}_{3}\right)$ was added to adjust the $\mathrm{pH}$ of the fermentation liquid to above 6.8. Afterwards, the $\mathrm{pH}$ of the high-temperature dry fermentation systems self-stabilized between 6.6-6.93, and the systems ran stably. During the stable period, the concentrations of VFAs were positively correlated with the concentrations of TS and increased to $56.45 \pm 2.98,71.11 \pm 5.25,69.33 \pm 3.99$, and $22.08 \pm 2.21 \mathrm{~g} / \mathrm{L}$, respectively, on day 120 .

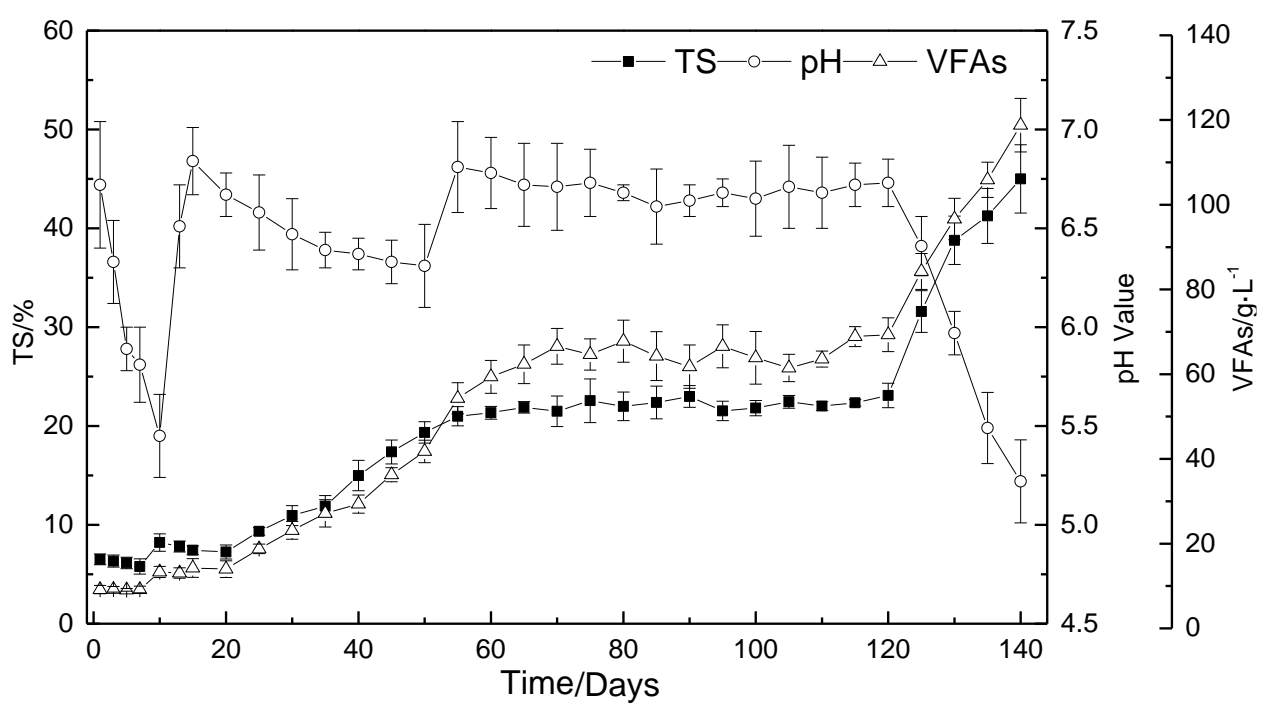

Figure 7. Changes in $p H, T S$ and VFAs concentrations in reactor $R 3$

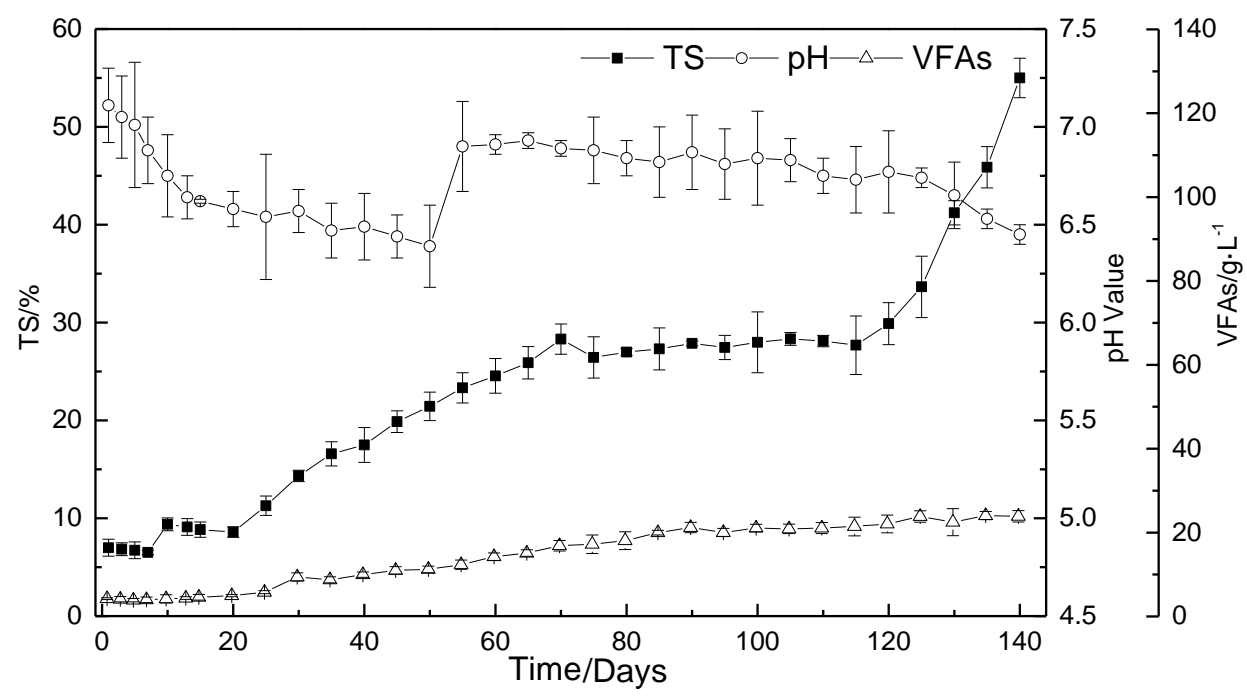

Figure 8. Changes in $p H, T S$ and VFAs concentrations in reactor $R 4$

In the stable period, feedstock was added and discharged from R1-4 every day. Only on the 51st day, the $\mathrm{pH}$ of the fermentation liquid was adjusted to above 6.8. Afterwards, the systems ran stably without $\mathrm{pH}$ adjustment. The main reason is that the 
metabolic activity of methanogenic bacteria was enhanced, and the high-temperature fermentation microorganisms grew evenly after the adaptation and fast start-up period. After the $\mathrm{pH}$ adjustment on day 51, the metabolic activity of methanogens was enhanced, and the organic acids generated from hydrolysis and acidification were directly consumed by methanogens to give methane. Therefore, the concentrations of organic acids increased in this stage, and the $\mathrm{pH}$ of these systems did not decline and kept constant between 6.6 and 6.93 because of the balance between the microorganisms (Luo and Li, 2018; Fan et al., 2008).

During the overload period, with higher amount of feedstock loaded, the TS concentrations in R1-4 increased significantly, resulting in a difficult discharge and decrease of $\mathrm{pH}$. VFAs could not be metabolized because the reactions were inhibited, resulting in the increase of VFAs contents to $92.37 \pm 4.59,128.32 \pm 7.32$, $118.79 \pm 6.33$, and $23.88 \pm 1.36 \mathrm{~g} / \mathrm{L}$ in $\mathrm{R} 1,2,3$ and 4 at the end of the reactions. Except that the biogas production rate in $\mathrm{R} 1$ was $0.7 \pm 0.02 \mathrm{~m}^{3} /\left(\mathrm{m}^{3} \cdot \mathrm{d}\right)$, biogas was not produced in reactors $\mathrm{R} 2, \mathrm{R} 3$, and $\mathrm{R} 4$. The main reason for the stagnation of hightemperature dry fermentation is that when the amount of feedstock loaded was increased, especially in reactors R2, R3, and R4 with straw as the feedstock, the large amounts of shredded straw absorbed water and expanded rapidly at high temperatures. This straw aggregated in the upper layer of CSTR reactors. Although the mixtures were violently stirred before discharging, the straw aggregated was difficult to discharge, resulting in the changes of the composition in these systems. The proportions of straw increased due to the retention of straw. In the last stage, the straw expanded was hard to stir and discharge. The systems were obviously rancid, which was sensed during the discharge process (Zhou et al., 2019). The accumulation of organic acids led to the decrease of $\mathrm{pH}$ in the systems, so the chicken manure and straw were directly discharged without biochemical degradation. Except R1, biogas was not produced in reactors $\mathrm{R} 2$, R3, and $\mathrm{R} 4$, and the high-temperature dry fermentation was terminated (Yang et al., 2017).

\section{Conclusion}

(1) In the adaptation period (20 days, from day 1 to 20 ), along with the loading with feedstock, the TS and VFAs concentrations, biogas production rates, and $\mathrm{pH}$ of the systems decreased, and the ammonia concentrations increased. At the end of the adaptation period, the biogas production rate in $\mathrm{R} 1, \mathrm{R} 2, \mathrm{R} 3$, and $\mathrm{R} 4$ was as low as $0.78 \pm 0.096,0.97 \pm 0.11,0.91 \pm 0.12$, and $0.34 \pm 0.20 \mathrm{~m}^{3} /\left(\mathrm{m}^{3} \bullet \mathrm{d}\right)$, respectively. The concentrations of methane in biogas increased to 47.21, 60.33, 54.35, and $45.33 \%$ on the 20th day, and HRT (day 1-20) was 200 days.

(2) During the fast start-up period (30 days, from day 21 to 50), semi-continuous anaerobic digestion took place. The TS concentration, biogas production rate, methane concentration, and VFAs concentration in reactor R2 increased with the increase of the loading frequency. At the end of the fast start-up period, the biogas production rate in reactors R1-3 and R4 was $1.71 \pm 0.12, \quad 2.14 \pm 0.18, \quad 2.01 \pm 0.08$, and $0.73 \pm 0.07 \mathrm{~m}^{3} /\left(\mathrm{m}^{3} \bullet \mathrm{d}\right)$ in $\mathrm{R} 1,2,3$ and 4 , respectively. The methane concentrations in biogas increased to $52.31,66.25,61.25$, and $53.33 \%$ on the 50th day. During the fast start-up period, the reactors were instable in operation, and the discharging and feeding could not be realized every day. The HRT (day 21-40) and HRT (day 41-50) values were 60 and 40 days, respectively. 
(3) During the stable period (70 days, from day 51 to 120), continuous digestion was realized, and the TS concentrations exceeded $20 \%$, in accordance with dry fermentation. In the stable period, the TS concentrations, biogas production rates, methane concentrations, $\mathrm{pH}$, and other parameters in the reactors were relatively stable. At the end of the stable period, the concentration of TS in reactors R1-3 and R4 increased to $21.38 \pm 0.85,22.33 \pm 1.98,23.096 \pm 1.23$, and $27.69 \pm 2.99 \%$, respectively. The biogas production rates maintained at 2.17-2.33, 2.40-2.63, 2.20-2.44, and $0.75-0.90 \mathrm{~m}^{3} /\left(\mathrm{m}^{3} \cdot \mathrm{d}\right)$, and the concentrations of methane in biogas maintained at levels of $53.33-57.22,64.34-68.88,61.18-66.37$, and $51.32-55.45 \%$ in $\mathrm{R} 1,2,3$ and 4 , respectively. The systems were stable in operation, and $\mathrm{pH}$ and daily biogas output were also stable and the HRT (day 51-120) value was determined to be 20 days.

\section{REFERENCES}

[1] Chen, Y., Cheng, J. J., Creamer, K. S. (2008): Inhibition of anaerobic digestion process: a review. - Bioresource Technology 99(10): 4044-4064.

[2] Chu, C.-F., Ebie, Y., Xu, K.-Q., Li, Y.-Y., Yuhei, I. (2010): Characterization of microbial community in the two-stage process for hydrogen and methane production from food waste. - International Journal of Hydrogen Energy 35(15): 8253-8261.

[3] Chunyang Zhang, Weidong Wang, Junqi Jia, Aihua Wang, Lingling Li (2017): Study on Recovery of Biogas from Distillers Grains Wastewater by USR Reactor. - Procedia Engineering 205.

[4] den Boer, E., den Boer, J., Jaroszynska, J., Szpadt, R. (2012): Monitoring of municipal waste generated in the city of Warsaw. - Waste Management and Research 30(8): 772780 .

[5] Duan, X., Wang, X., Xie, J., Feng, L., Yan, Y., Zhou, Q. (2016): Effect of nonylphenol on volatile fatty acids accumulation during anaerobic fermentation of waste activated sludge. - Water Research 105: 209-217.

[6] Duan, X., Wang, X., Xie, J., Feng, L., Yan, Y., Zhou, Q. (2016): Effect of nonylphenol on volatile fatty acids accumulation during anaerobic fermentation of waste activated sludge. - Water Research 105: 209-217.

[7] Fan, L., Pan, J. H., Li, M. S., et al. (2008): Lactate inhibits hydrolysis of polysaccharide rich particulate organic waste. - Bioresource Technology 99(55): 2476-2482.

[8] Feng, L., Li, R. D. (2013): Process parameters of dry co-anaerobic digestion of kitchen waste and cow manure on laboratory scale. - Journal of Pure and Applied Microbiology 21(9): 777-782.

[9] García-Ochoa, F., Santos, V. E., Naval, L., Guardiola, E., López, B. (1999): Kinetic model for anaerobic digestion of livestock manure. - Enzyme and Microbial Technology 25(1).

[10] Hu, J., Xu, Q., Li, X., Wang, D., Zhong, Y., Zhao, J., Zhang, D., Yang, Q., Zeng, G. (2018): Sulfamethazine (SMZ) affects fermentative short-chain fatty acids production from waste activated sludge. - Science of the Total Environment 639: 1471-1479.

[11] Hua, W., Yong, P. (2009): Water quantity operation to achieve multi-environmental goals for a waterfront body. - Water Resources Management 23(10): 1951-1968.

[12] Jiménez, A. M., Borja, R., Martín, A. (2003): Aerobic-anaerobic biodegradation of beet molasses alcoholic fermentation wastewater. - Process Biochemistry 38(9).

[13] Li, Y., Jin, Y., Li, J., Chen, Y., Gong, Y., Li, Y., Zhang, J. (2016): Current situation and development of kitchen waste treatment in China. - Procedia Environmental Sciences 31: 40-49.

[14] Linke, B. (2006): Kinetic study of thermophilic anaerobic digestion of solid wastes from potato processing. - Biomass and Bioenergy 30(10): 892-896. 
[15] Lu, J., Jiang, L. N., Chen, D. J., Toyota, K., Strong, J., Wang H. L., Hirasawa T. (2012): Decontamination of anaerobically digested slurry in a paddy field ecosystem in Jiaxing region of China. - Agriculture, Ecosystems \& Environment 146(1): 13-22.

[16] Luo, H., Li, F. S. (2018): Tomato yield, quality, and water use efficiency under different drip fertigation strategies. - Scientia Horticulturae 235: 181-188.

[17] Naranjo, A., et al. (2011): Effects of different concentrations of $\mathrm{NaOH}$ pretreatment on anaerobic digestion of rice straw for biogas production. - Transactions of the Chinese Society of Agricultural Engineering 27(10): 59-63.

[18] Nasir, I. M., Ghazi, T. I. M., Omar, R. (2012): Production of biogas from solid organic wastes through anaerobic digestion: a review. - Applied Microbiology and Biotechnology 95(2): 321-329.

[19] Pontes, R. F. F., Pinto, J. M. (2006): Analysis of integrated kinetic and flow models for anaerobic digesters. - Chemical Engineering Journal 122(1): 65-80.

[20] Rundberget, T., Skaar, I., Flaoyen, A. (2004): The presence of Penieillum and Penicillum mycotoxins in food waste. - International Journal of Food Microbiology 53(90): 181-188.

[21] Tauseef, S. M., Abbasi, T., Abbasi, S. A. (2013): Energy recovery from wastewaters with high-rate anaerobic digesters. - Renewable and Sustainable Energy Reviews 19: 704-741.

[22] Wang, D., Zhang, D., Xu, Q., Liu, Y., Wang, Q., Ni, B.-J., Yang, Q., Li, X., Yang, F. (2018): Calcium peroxide promotes hydrogen production from dark fermentation of waste activated sludge. - Chemical Engineering Journal 355: 22-32.

[23] Yang, S. F., Phan, H. V., Bustamante, H., Guo, W. S., Ngo, H. H., Nghiem, L. D. (2017): Effects of shearing on biogas production and microbial community structure during anaerobic digestion with recuperative thickening. - Bioresour. Technol. 234: 439-447.

[24] Yeoung, S. Y. (2005): High rate slurry phase decomposition of food wastes: indirect Performance estimation from dissolved oxygen. - Process Biochemistry 40(3): 13011306.

[25] Zhang L., Jahng, D. (2012): Long-term anaerobic digestion of food waste stabilized by trace elements. - Waste Management 32(8): 1509-1515.

[26] Zheng, J., Zhang, E. J., Wang, Y., et al. 2018. Analysis on the transport characteristics of water-biogas slurry integrated infiltration. - Journal of Lanzhou University of Technology 44(1): 58-64.

[27] Zhou, M., Yang, H. N., Zheng, D., Pu, X. D., Liu, Y., Wang, L., Zhang, Y. H., Deng, L. W. (2019): Methanogenic activity and microbial communities characteristics in dry and wet anaerobic digestion sludges from swine manure. - Biochem. Eng. J. 152(15): 107116. 